\title{
Intimate Partner Violence (IPV) in Zambia: Socio-demographic Determinants and Association with Use of Maternal Health Care
}

\author{
Simona Simona ${ }^{1}$, Mazuba Muchindu $^{1}$, Harriet Ntalasha ${ }^{1}$ \\ ${ }^{1}$ Department of Social Work and Sociology, University of Zambia, Zambia \\ Correspondence: Simona Simona, Department of Social Work and Sociology, University of Zambia, Zambia
}

Received: April 5, 2018

Accepted: May 17, 2018

Available online: May 25, 2018

doi:10.11114/ijsss.v6i6.3300

URL: https://doi.org/10.11114/ijsss.v6i6.3300

\begin{abstract}
This study used the 2013-2014 Zambia Demographic and Health Survey (ZDHS) data to examine, on one hand, the socio-demographic characteristics associated with intimate partner violence (IPV) and, on the other hand, the relationship between IPV and maternal health care (place of delivery and ANC visits) utilization. The findings indicate that women's characteristics including marital status, household wealth, witnessing parental violence and attitudes justifying wife beating were significantly associated with reporting experience of IPV. Partner characteristics significantly associated with IPV were alcohol consumption and jealous behaviour. In this study, IPV was not found to be strongly associated with use of maternal health care. The study indicates that gender inequality and problematic cultural norms that privilege men with power over women still exist in Zambia, and thus IPV preventive strategies should incorporate means of toning down such norms to enhance the welfare of women.
\end{abstract}

Keywords: Intimate partner violence, gender inequality, maternal health care, norms, Zambia

\section{Introduction}

Intimate Partner Violence (IPV), defined as lifetime experience of violence by an intimate partner, is a global social and public health problem, perpetrated mostly by men against women (Krug, Mercy, Dahlberg and Zwi, 2002; Tuladhar, Khanal, Lila, Ghimire and Onta, 2013). Globally, the lifetime prevalence of violence against women is averaging 35.6\% (WHO, 2013) and in sub-Saharan Africa, the prevalence of IPV ranges between $20 \%$ and $70 \%$ (Devries, Mak, Garcia-Moreno, Petzold, Child, ...Watts, 2013). In Zambia, evidence shows that $43 \%$ of women age 15-49 have experienced physical violence and that 37\% experienced physical violence in the 12 months preceding the 2013-2014 Zambia Demographic and Health Survey (ZDHS) (CSO, 2014).

Many studies have examined predictors of intimate partner violence in different parts of the world. The documented factors of IPV operate on different levels, ranging from individual socio-demographic characteristics to culturally related factors, particularly in the African context. Commonly reported socio-demographic factors that are positively associated with IPV include woman's age (Kwagala, Wandera, Ndugga and Kabagenyi, 2013), childhood experience of domestic violence (Yount and Carrera, 2006), having a low level of education, being unemployed, financial dependence on the partner (Dutton, 1988; Gartner, 1999; Smith, 1990), using drugs or drinking alcohol (Koenig, Lutalo, Zhao, Nalugoda and Wabwire-Mangen, 2006; Kwagala et al, 2013), and having more surviving children (Hindin, Kishor and Ansara, 2008).

Lower levels of education and unemployment are both seen as contributing to women's frequent dependence on their husbands and partners, thereby making it difficult for them to leave situations of domestic violence. These factors also make women more tolerant of spousal abuse, hence putting them in a vicious cycle of violence and abuse. However, there have been contradictory findings on the association between education and IPV. Some studies have found that some women with lower educational status compared with their partners are at a higher risk of violence (Garcia-Moreno, Jansen, Ellsberg, Heise and Watts, 2005) and other studies have found that women with higher educational status than their partners are at higher risk of violence (Jewkes, Levin and Penn-Kekana, 2002; Taillieu and Brownridge, 2010). 
Other factors associated with women's likelihood of being victims of IPV include marrying at a young age, lack of contact with natal kin, witnessing abuse of one's mother (Felson and Messne, 2000) and being more than 10 years younger than one's partner (Lawoko, Dalal, Jiayou and Jansson, 2007).

Cultural factors associated with IPV include justification for wife beating for various reasons, including disobedience or refusal of sex (Shezongo-Macmillan, 2007), male controlling behaviour, and control over family resources and the means of production (Jewkes et al., 2002; Taillieu and Brownridge, 2010). However, some studies also show that women who have control over these resources are not protected from IPV (Vyas and Watts, 2009).

Cultural factors in Africa have been explained by institutionalised gender inequalities that privilege men with power over women in decision-making (Ofei-Aboagye, 1994; Hinden, 2003; Suffitz, 2010). These culturally-entrenched gender inequalities relegate women to subordinate positions, thereby exacerbating their vulnerability to domestic violence. Zambia being a patriarchal society, similar discourses of gender inequality are commonplace (OMCT, 2002; Simpson, 2005).

Women's experience of IPV has been associated with poor sexual and reproductive health outcomes, such as sexually transmitted infections (STIs), including HIV (Campbell, 2002), pregnancy complications and abortion (Emenike, Lawoko and Dalal, 2008), urinary tract infections (Campbell, 2002), and sexual dysfunction (UNICEF, 2000). The experience of IPV also has an indirect effect on maternal health by making it difficult for women to access a variety of maternal health care services. Several studies in developing countries have established the relationship between IPV and maternal health care services. In a study exploring the relationship between maternal experiences of physical and sexual IPV and the use of reproductive health care services in Bangladesh, Rahman, Nakamura, Seina and Kizuki (2012) found an association between maternal IPV experiences and the low use of ANC. Women who had been sexually abused were significantly less likely to have visited a skilled ANC and delivery care provider. The more severe the violence, the more profound were the consequences. In Nigeria Ononokpono and Azfredrick (2014) also found significant associations between IPV and the use of maternal health care services. They found that women who had ever experienced physical or emotional IPV were significantly less likely to use adequate ANC and delivery assistance by a skilled health care provider.

One of the main arguments given to explain the relationship between IPV and maternal health care indicators is that violence can affect a woman's emotional and physical health, and this in turn may lead to lack of incentive to pursue appropriate maternal health care (Rahman et al., 2012; Ononokpono and Azfredrick, 2014). This seems to be common in countries with value systems that emphasize male dominance and subordination of women. In a study on use of maternal health care services in Nicaragua, for example, Lubbock and Stephenson (2008) found that men had the authority both in the workplace and in the home to dictate women's mobility and autonomy in accessing maternal health care services. They could deny women permission to seek care if, for example, they were examined by a male health practitioner, due to jealousy. Therefore, in many instances women would choose not to go for health care, to avoid potential violence or conflict with their partners.

However, some studies report conflicting findings on the relationship between IPV and use of maternal health services as evidenced in a study by Ononokpono and Azfredrick (2014) in Nigeria which found no significant relationship between sexual IPV and use of maternal health care services.

Given the conflicting results on the relationship between IPV and maternal health care and the fact that there are still relatively few studies done on the subject, there is need for further examination. The current study uses a national sample to examine factors associated with IPV and how IPV is associated with maternal health care will therefore provide current information not only to fill the literature gaps but also for policy intervention.

\subsection{Conceptual Framework}

A conceptual framework is shown in Figure 1 and it highlights common individual factors that are consistently associated with a women's likelihood of experiencing violence perpetrated by her partner(s) and relationship factors, particularly partner characteristics that lead to IPV. The model then looks at how IPV in turn leads to low use of maternal health services. The socio-demographic factors examined in the study are those covered in DHS data. For women, these are area or residence, age, marital status, number living children, education, employment, wealth witnessing parental violence and justifying wife beating attitudes. For partner characteristics we included educational attainment, alcohol consumption, occupation and jealous behaviour. It is acknowledged that while some of these may have a strong relationship, others may not. On the relationship between IPV and maternal health, we were guided by the IPV contextual framework proposed by Bell and Naugle 2008. According to this model, consequences of IPV include increasing the partner's compliant behaviour, thus escaping or avoiding arguments, termination of the relationship, and physical injury (Bell and Naugle, 2014). A woman may therefore opt not to go for an ANC visit or use other maternal health care services to avoid violence from her partner. 


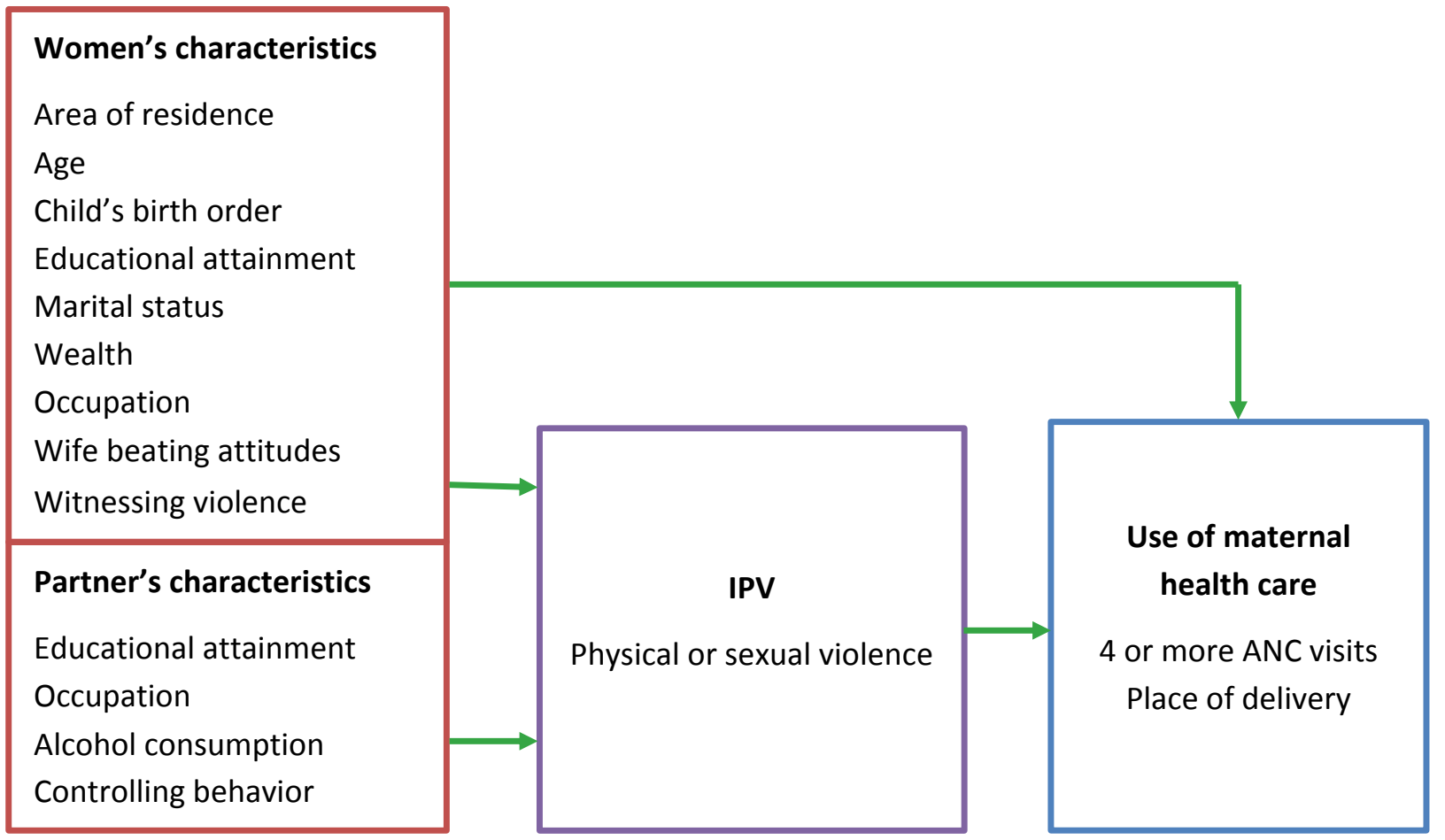

Figure 1. Conceptual framework for intimate partner violence and use of maternal health care services

\subsection{Research Questions}

This study addresses the following research questions:

1. Which socio-demographic factors are associated with intimate partner violence among women age 15-49?

2. What is the relationship between Intimate Partner Violence and use of maternal health services among women aged $15-49$ ?

\section{Methods}

Data for this study were derived from the 2013-2014 Zambia Demographic and Health Survey (ZDHS). The survey is nationally representative and was organised under the auspices of the Central Statistical Office (CSO), Ministry of Health, and ICF International in partnership with other governmental and non-governmental organisations in Zambia. The data collected through the survey include background characteristics, marriage and sexual activity, fertility, family planning, maternal health, nutrition, HIV/AIDS, and domestic violence. The study made use of the individual women's recodes, from the survey module on domestic violence.

\subsection{Sample Size and Sampling Procedure}

The 2013-2014 ZDHS used a two-stage sampling design with a sampling frame from the Zambia 2010 Census of Population and Housing (CPH, 2010). Since the country has 10 provinces, 20 strata were created representing urban and rural areas in each province. The survey selected 722 Standard Enumeration Areas (SEA) from the strata in the first-stage of the selection process, from which 18,050 households were selected. The total number of women age 15-49 interviewed was 16,411 .

The domestic violence module was administered to one randomly selected woman in each selected household. The total number of women who answered the domestic violence module in the ZDHS was 11,778. These women were asked about their experiences of violence. Since our focus is on intimate partner violence and maternal health use, we restricted the analysis to women who reported to have ever been married and who had a live birth in the five years preceding the survey. The total number of women included in the study is 7,005 (weighted $=6,087$ ).

\subsection{Dependent Variables}

There are three dependent variables for this study: intimate partner violence (IPV), place of delivery, and number of antenatal care (ANC) visits. IPV is defined as ever experiencing physical or sexual violence. Physical and sexual violence were selected because they are the most occurring forms of IPV in Zambia (Central Statistical Office, Ministry of Health, and ICF International, 2014). Other forms include emotional (psychological) abuse and controlling behaviours. Ever experiencing physical violence was determined by the respondent answering "yes" to any of a string 
of questions about whether her spouse ever: a) slapped her; b) twisted her arm or pulled her hair; c) pushed, shook, or threw something at her; d) punched her with his fist or something that could hurt her; e) kicked her, dragged her, or beat her up; f) tried to choke her or burned her on purpose; or g) threatened her or attacked her with a knife, gun, or any other weapon. Experiencing sexual violence was determined by the respondent answering "yes" to any of the two questions that asked whether the woman's spouse had ever forced her to have sexual intercourse or to perform any sexual activity without her will.

Data on place of delivery were collected for all births in the five years preceding the survey, but the analysis focused on the care that women received for their most recent birth. It was measured by the survey question that asked women where they delivered their more recent birth. If a woman answered home or other home, it was recoded as "home" and all kinds of conventional health facilities were recoded as "facility delivery".

ANC visits were measured using the question that asked women how many times they received antenatal care during the pregnancy for the most recent birth. If they received no ANC care or made one to three ANC visits, this was recoded as " 0 ", and if they made four or more antenatal care visits, this was recoded as " 1 ".

\subsection{Independent Variables}

There are two sets of independent variables in this study. The variables were chosen because their theoretical relevance and presence in the DHS dataset. The first set considers IPV as the dependent variable and selected socio-demographic characteristics as independent variables. These includes women's characteristics (current age, marital status, wealth index, educational attainment, religion, occupation, area of residence, alcohol consumption, witnessing parental violence and attitudes toward wife beating) and partners' characteristics (educational attainment, alcohol consumption, jealous behaviour and occupation).

Current age was defined as the age of the respondent at the time of the interview and it was categorised into three groups (15-24, 25-34, 35-49). Marital status was defined as women's marital status at the time of the survey and wealth index was a composite variable which was calculated from ownership of selected household asserts and was divided into five quintiles as poor, poorest, middle, rich and richest. Educational attainment was defined as the respondent's highest level of education and was recoded as no education, primary education and higher. Occupation was defined as employment status in the past 12 months prior to the survey and was categorised as not employed, employed for cash and self-employed in agriculture. Area of residence was dived into rural and urban and alcohol consumption was derived from the question which asked women whether they drink alcohol and it was recoded as a dichotomous variable, "yes" and "no". Attitude towards wife beating was measured by questions asking respondents whether wife beating was justified for the following reasons: if the wife a) goes out without informing the partner; b) neglects children; c) refuses to have sex; d) argues with partner. A composite variable was created that combined answers to all the four questions and it categorised as "yes" and "no". Partner characteristics were also recoded in a similar manner apart from jealous behaviour which was derived from a question that asked respondents whether their partners were jealous when they spoke to other men and it was recoded as "yes" and "no".

The second set considers use of maternal healthcare (place of delivery and ANC visits) as the dependent variables while IPV and selected socio-demographic characteristics were independent variables. The socio-demographic characteristics included are area of residence, wealth index, mother's age, child's birth order and educational attainment. These were selected to be controlled for because they have been associated with use maternal health care in previous studies.

\subsection{Statistical Analysis}

The study used Stata 13 for analysing the data. The analysis began with univariate analysis, where descriptive statistics of socio-demographic characteristics of the respondents were obtained. Frequency distributions and proportions of each independent variable against the dependent variables were determined, followed by ascertaining associations between each independent variable against dependent variables, using chi-square. To obtain and ascertain the strength of associations, logistic regression models with $95 \%$ odd ratio confidence intervals were used. Three regression models were run. The first had IPV as the dependent variable and socio-demographic and partner characteristics as independent variables. The second model had ANC visits as the dependent variable and IPV as the independent variable, along with other women's characteristics. The third model had place of delivery as the dependent variable and IPV as an independent variable, while adjusting for the influence of selected socio-demographic variables.

To address the issue of disproportionate sampling and non-response, the domestic violence sample weight was applied in the analysis. The svy commands were applied to adjust for the effects of a complex sampling design (two-stage sampling design) that was used in the 2013-2014 ZDHS. Ignoring the sampling design has an effect of underestimating the sampling errors, which consequently obscures the decision on whether or not to reject the null hypothesis. The Variance Inflator Factor (VIF) was used to diagnose multicollinearity among the covariates in each model. 


\subsection{Ethics}

Permission to use the 2013-2014 dataset was granted by the DHS Program which provides technical assistance to the DHS and hosts the data. There was no need to obtain any ethical clearance for the secondary analysis. All ethical protocols were fulfilled by ICF International and Central Statistical Office in Zambia during the initial stages of primary data collection (Central Statistical Office, Ministry of Health, and ICF International, 2014).

\section{Results}

\subsection{Background Characteristics of the Participants}

Table 1 reports the background characteristics of the sample population for this study. Nearly two-thirds of the women $(63 \%)$ resided in rural areas and almost half (47\%) were age 25-34. Mother's age at the most recent birth was mostly $20-34(69 \%)$, and for about one-third of the respondents $(34 \%)$ their most recent birth was their second or third, while for only $14 \%$ of respondents the most recent birth was their first.

Most of the women had attained primary education (57\%), were married (89\%), and were Protestants (82\%). About two-thirds $(65 \%)$ were in the lowest three categories of the wealth index, while about half $(49 \%)$ were employed for cash and 42\% were not employed. Most of respondent's husbands were employed for cash (75\%), and most had attained at least secondary education (51.6\%).

Table 1. Background characteristics of the participants

\begin{tabular}{|c|c|c|}
\hline Background characteristics & Number of women & $\%$ \\
\hline \multicolumn{3}{|l|}{ Woman's characteristics } \\
\hline \multicolumn{3}{|l|}{ Area of residence } \\
\hline Urban & 2251 & 37.0 \\
\hline Rural & 3836 & 63.0 \\
\hline \multicolumn{3}{|l|}{ Current age } \\
\hline $15-24$ & 1677 & 27.6 \\
\hline $25-34$ & 2879 & 47.3 \\
\hline $35-49$ & 1531 & 25.1 \\
\hline \multicolumn{3}{|c|}{ Mother's age for most recent birth } \\
\hline$<20$ & 807 & 13.3 \\
\hline $20-34$ & 4180 & 68.7 \\
\hline $35+$ & 1100 & 18.0 \\
\hline \multicolumn{3}{|l|}{ Birth order } \\
\hline $1^{\text {st }}$ & 876 & 14.4 \\
\hline $2^{\text {na }}$ or $3^{\text {ra }}$ & 2088 & 34.3 \\
\hline $4^{\text {th }}$ or $5^{\text {th }}$ & 1525 & 25.1 \\
\hline $6^{\text {th }}$ or more & 1598 & 26.3 \\
\hline \multicolumn{3}{|l|}{ Educational attainment } \\
\hline No education & 662 & 10.9 \\
\hline Primary & 3450 & 56.7 \\
\hline Higher & 1975 & 32.4 \\
\hline \multicolumn{3}{|l|}{ Marital status } \\
\hline Married & 5386 & 88.5 \\
\hline Widowed & 124 & 2.0 \\
\hline Divorced & 388 & 6.4 \\
\hline Separated & 189 & 3.1 \\
\hline \multicolumn{3}{|l|}{ Household wealth index } \\
\hline Poorest & 1398 & 23.0 \\
\hline Poor & 1316 & 21.6 \\
\hline Middle & 1236 & 20.3 \\
\hline Rich & 1165 & 19.1 \\
\hline Richest & 972 & 16.0 \\
\hline \multicolumn{3}{|l|}{ Religion } \\
\hline Catholic & 1012 & 16.6 \\
\hline Protestant & 4984 & 81.9 \\
\hline Muslim/other & 91 & 1.5 \\
\hline \multicolumn{3}{|c|}{ Occupation in the past 12 months } \\
\hline Not employed & 2537 & 41.7 \\
\hline Employed for cash & 2956 & 48.6 \\
\hline Self-employed agriculture & 594 & 9.8 \\
\hline \multicolumn{3}{|l|}{ Alcohol consumption } \\
\hline No & 5524 & 90.8 \\
\hline Yes & 563 & 9.2 \\
\hline
\end{tabular}




\begin{tabular}{|c|c|c|}
\hline \multicolumn{3}{|l|}{ Wife beating justifiable } \\
\hline No & 2994 & 49.2 \\
\hline Yes & 3090 & 50.8 \\
\hline \multicolumn{3}{|l|}{ Witnessed parental violence } \\
\hline No & 3293 & 54.1 \\
\hline Yes & 2218 & 36.4 \\
\hline Do not know & 576 & 9.5 \\
\hline \multicolumn{3}{|c|}{ Husband's characteristics } \\
\hline \multicolumn{3}{|c|}{ Husband's educational attainment } \\
\hline No education & 565 & 9.3 \\
\hline Primary & 2380 & 39.1 \\
\hline Higher & 3142 & 51.6 \\
\hline \multicolumn{3}{|l|}{ Husband jealous } \\
\hline No & 2139 & 35.2 \\
\hline Yes & 3889 & 63.9 \\
\hline Don't know & 59 & 1.0 \\
\hline \multicolumn{3}{|l|}{ Husband's occupation } \\
\hline Not employed & 428 & 7.0 \\
\hline Employed for cash & 4556 & 74.8 \\
\hline Self-employed agriculture & 1103 & 18.1 \\
\hline \multicolumn{3}{|c|}{ Husband's alcohol consumption } \\
\hline No & 3318 & 54.5 \\
\hline Yes & 2769 & 45.5 \\
\hline
\end{tabular}

3.2 Intimate Partner Violence and Women's Socio-demographic Characteristics

The bivariate analysis revealed a number of significant relationships between women's socio-demographic characteristics and their experience of IPV. Table 2 shows that women's educational attainment, marital status, and occupation in the 12 months preceding the survey were strongly associated with experiencing IPV. Levels of IPV were higher among women with less than eight years of education, among women who were divorced or separated compared with currently married women, and among women who were employed in the last 12 months, whether for cash or self-employed, compared with women who were not employed.

The results also show that women who consumed alcohol, women who responded that wife beating is justifiable, and women who had witnessed their mothers being beaten by their fathers reported significantly higher levels of ever experiencing IPV. Women whose husbands were self-employed, consumed alcohol, or were jealous reported higher lifetime experience of IPV. In contrast, urban or rural residence, age, wealth index status, and educational attainment were not associated with ever experiencing IPV.

Table 2. Percentage of women who had experience of intimate partner violence by background characteristics

\begin{tabular}{|c|c|c|}
\hline & \multicolumn{2}{|c|}{ Intimate partner violence } \\
\hline & $\%$ & Number of women \\
\hline \multicolumn{3}{|l|}{ Woman's characteristics } \\
\hline \multicolumn{3}{|l|}{ Area of residence } \\
\hline Urban & 42.9 & 966 \\
\hline Rural & 43.4 & 1664 \\
\hline \multicolumn{3}{|l|}{ Current age } \\
\hline $15-20$ & 43.0 & 720 \\
\hline $25-34$ & 44.0 & 1267 \\
\hline $35-49$ & 42.0 & 644 \\
\hline \multicolumn{3}{|l|}{ Educational attainment } \\
\hline No education & 42.8 & 283 \\
\hline Primary & 45.2 & 1560 \\
\hline Higher & 39.9 & 787 \\
\hline \multicolumn{2}{|l|}{ Marital status } & $* * *$ \\
\hline Married & 41.9 & 2256 \\
\hline Widowed & 43.6 & 47 \\
\hline Divorced & 56.7 & 220 \\
\hline Separated & 58.2 & 110 \\
\hline \multicolumn{3}{|l|}{ Wealth } \\
\hline Poorest & 44.5 & 621 \\
\hline Poor & 42.4 & 559 \\
\hline Middle & 47.2 & 583 \\
\hline Rich & 42.3 & 492 \\
\hline Richest & 38.6 & 375 \\
\hline
\end{tabular}




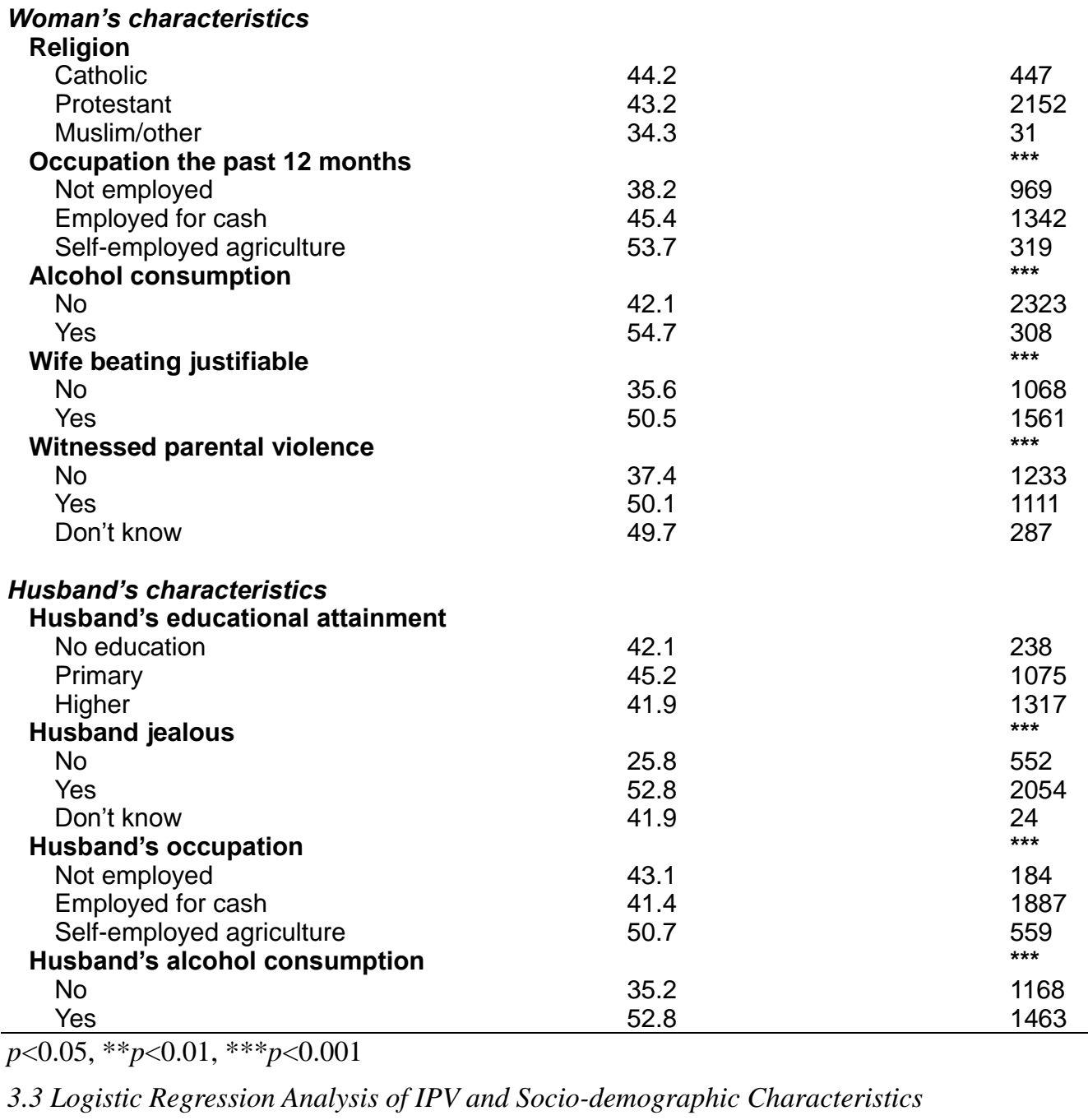

Table 3 presents the results of logistic regression analysis of IPV and socio-demographic characteristics. The results show that women who are divorced $(p<0.01)$ or separated $(p<0.05)$ have significantly higher odds of reporting ever experiencing IPV compared with married women. Lifetime experience of IPV is also significantly associated with household wealth: Women in the middle wealth quintile $(p<0.01)$ have higher odds of reporting violence compared with those in the poorest quintile. The study shows interesting findings about women's employment and IPV: Women employed for cash $(p<0.01)$ and those who are self-employed in agriculture $(p<0.01)$ have significantly higher odds of reporting ever experiencing violence than women who are not employed. Also, as expected, women who responded that wife beating is justifiable have higher odds of reporting violence compared with those without this attitude, and women who reported that they had witnessed marital violence between their parents have higher odds compared with women who had not been exposed to parental violence.

Concerning husband's characteristics, the findings indicate that jealousy and alcohol consumption by the husband are each significantly associated with women's reporting ever experiencing IPV. Women with jealous husbands $(p<0.001)$ and women with partners who consume alcohol $(p<0.001)$ have higher odds of reporting ever experiencing IPV. All other variables studied were not found to be significantly associated with IPV. 
Table 3. Logistic regression results of IPV on woman's and husband's characteristics

\begin{tabular}{|c|c|c|}
\hline & Ever experi & \\
\hline Variable & Odds ratio & $95 \% \mathrm{Cl}$ \\
\hline Women's characteristics & & \\
\hline Area of residence & & \\
\hline Urban & 1 & \\
\hline Rural & 0.91 & $(0.74-1.12)$ \\
\hline Current age & & \\
\hline $15-24$ & 1 & \\
\hline $25-34$ & 0.98 & $(0.84-1.15)$ \\
\hline $35-49$ & 0.82 & $(0.66-1.03)$ \\
\hline Educational attainment & & \\
\hline No education & 1 & \\
\hline Primary & 1.03 & $(0.83-1.24)$ \\
\hline Higher & 0.80 & $(0.62-1.04)$ \\
\hline Marital status & & \\
\hline Married & 1 & \\
\hline Widowed & 0.76 & $(0.47-1.21)$ \\
\hline Divorced & 1.64 & $(1.23-2.19)$ ** \\
\hline Separated & 1.71 & $(1.08-2.72) *$ \\
\hline Wealth & & \\
\hline Poorest & 1 & \\
\hline Poor & 1.08 & $(0.91-1.28)$ \\
\hline Middle & 1.32 & $(1.09-1.62)^{\star \star}$ \\
\hline Rich & 1.29 & $(0.99-1.68)$ \\
\hline Richest & 1.11 & $(0.77-1.60)$ \\
\hline Religion & & \\
\hline Catholic & 1 & \\
\hline Protestant & 1.11 & $(0.94-1.31)$ \\
\hline Muslim/other & 0.80 & $(0.42-1.52)$ \\
\hline Occupation in the past $12 \mathrm{r}$ & & \\
\hline Not employed & 1 & \\
\hline Employed for cash & 1.28 & $(1.11-1.47)^{\star \star}$ \\
\hline Self-employed agriculture & 1.52 & $(1.17-1.97)^{\star \star}$ \\
\hline Alcohol consumption & & \\
\hline No & 1 & \\
\hline Yes & 1.21 & $(0.95-1.54)^{\star \star *}$ \\
\hline Wife beating justifiable & & \\
\hline No & 1 & \\
\hline Yes & 1.44 & $(1.24-1.66)^{\star \star \star}$ \\
\hline Witnessed parental violenc & & \\
\hline No & 1 & \\
\hline Yes & 1.55 & $(1.35-1.78)^{\star * *}$ \\
\hline Don't know & 1.49 & $(1.17-1.91)^{\star \star}$ \\
\hline Husband's characteristics & & \\
\hline $\begin{array}{l}\text { Husband's educational atta } \\
\text { No education }\end{array}$ & & \\
\hline Primary & 1.22 & $(0.98-1.53)$ \\
\hline Higher & 1.10 & $(0.87-1.39)$ \\
\hline Husband jealous & & \\
\hline No & & \\
\hline Yes & 2.69 & $(2.31-3.14)^{\star \star \star}$ \\
\hline Don't know & 1.78 & $(0.71-4.47)$ \\
\hline Husband's occupation & & \\
\hline Not employed & 1 & \\
\hline Employed for cash & 0.97 & $(0.73-1.28)$ \\
\hline Self-employed agriculture & 1.17 & $(0.84-1.62)$ \\
\hline Husband's alcohol consum & & \\
\hline No & 1 & \\
\hline Yes & 1.83 & $(1.59-2.10)^{\star \star \star}$ \\
\hline
\end{tabular}

3.4 Intimate Partner Violence and Use of Maternal Health care

Among ever-married women with a recent birth, $40 \%$ reported ever experiencing physical violence by their intimate partners, and $17 \%$ reported experiencing sexual violence. More than four women in every ten $(43 \%)$ reported ever 
experiencing physical or sexual violence. In terms of maternal health care, nearly three-quarters $(70 \%)$ of ever-married women who gave birth in the five years before the survey delivered in a health facility, and more than half (55\%) made four or more antenatal care visits to a health facility.

Figure 2 indicates that there is no relationship between number of ANC visits and reporting ever experiencing IPV. However, there is a significant relationship between place of delivery and reporting ever experiencing IPV, in that women who report ever experiencing IPV are significantly less likely to deliver at a health facility.

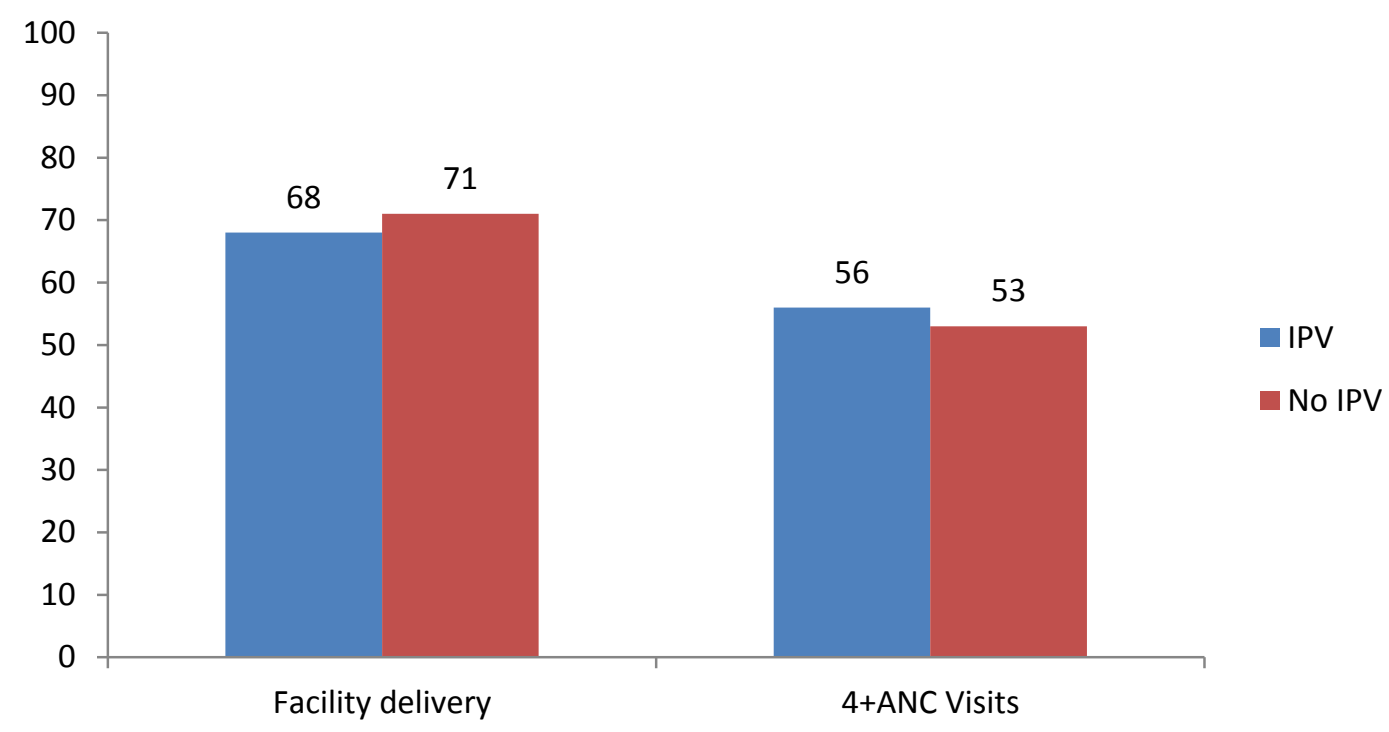

Figure 2. Percentage of women who used maternal health care services by experience of IPV

Table 4. Multiple logistic regression results of use of maternal health care

\begin{tabular}{|c|c|c|}
\hline \multirow[b]{2}{*}{ Variable } & \multicolumn{2}{|c|}{ Maternal health care use } \\
\hline & $\begin{array}{l}\text { Facility delivery } \\
\text { Odds ratio }(95 \% \mathrm{Cl})\end{array}$ & $\begin{array}{l}4 \text { or more ANC visits } \\
\text { Odds ratio }(95 \% \mathrm{Cl})\end{array}$ \\
\hline \multicolumn{3}{|r|}{ (2) } \\
\hline No & 1 & 1 \\
\hline Yes & $0.91(0.79-1.05)$ & $0.93(0.81-1.06)$ \\
\hline \multicolumn{3}{|c|}{ Area of residence } \\
\hline Urban & 1 & \\
\hline Rural & $0.38(0.29-0.50)^{\star \star \star}$ & $1.40(1.14-1.71)^{\star *}$ \\
\hline \multicolumn{3}{|c|}{ Mothers age at birth } \\
\hline$<20$ & 1 & \\
\hline $20-34$ & $1.78(1.28-2.47)^{\star *}$ & $1.17(0.90-1.53)$ \\
\hline $35+$ & $1.71(1.15-2.53)^{\star *}$ & $1.31(0.94-1.82)$ \\
\hline \multicolumn{3}{|l|}{ Birth order } \\
\hline $1^{\text {st }}$ & 1 & 1 \\
\hline 2nd or 3rd & $0.48(0.33-0.62)^{\star \star \star}$ & $0.83(0.67-1.06)$ \\
\hline $4^{\text {tn }}$ or 5 th & $0.42(0.30-0.41)^{* * *}$ & $0.91(0.69-1.19)$ \\
\hline $6^{\text {th }}$ or more & $0.29(0.20-0.41)^{\star \star \star}$ & $0.93(0.69-1.26)$ \\
\hline \multicolumn{3}{|c|}{ Woman's educational attainment } \\
\hline No education & 1 & \\
\hline Primary & $1.19(0.96-1.49)$ & $1.25(1.03-1.46)^{*}$ \\
\hline Higher & $2.05(1.56-2.69)^{\star * *}$ & $1.26(1.00-1.58)^{*}$ \\
\hline \multicolumn{3}{|l|}{ Wealth } \\
\hline Poorest & 1 & 1 \\
\hline Poor & $1.22(1.03-1.46)^{*}$ & $1.22(1.03-1.46)^{\star}$ \\
\hline Middle & $1.18(0.96-1.45)$ & $1.30(1.08-1.56)^{\star *}$ \\
\hline Rich & $1.81(1.35-2.42)^{\star \star *}$ & $1.31(1.03-1.66)^{*}$ \\
\hline Richest & $3.52(2.01-6.15)^{\star \star \star}$ & $2.37(1.73-3.23)^{\star * *}$ \\
\hline \multicolumn{3}{|l|}{ ANC Visits } \\
\hline $0-3$ & 1 & \\
\hline 4 or more & $1.41(1.22-1.63)^{\star * *}$ & \\
\hline
\end{tabular}




\subsection{Multiple Logistic Regressions of IPV and Use of Maternal Health Care}

Table 4 presents the logistic regression of IPV and use of maternal health care (place of delivery and ANC visits). The first model reports the relationship between IPV and place of delivery, while adjusting for area of residence, mother's age for the most recent birth, birth order, educational attainment, wealth, and number of ANC visits. The results show that after adjusting for the covariates, the odds of delivering in a health facility for women who reported ever experiencing IPV are not significantly different from those of women who never experienced IPV.

The same results are observed in the second model, when ANC visits and the same covariates are considered. After adjusting for area of residence, mother's age for the most recent birth, birth order, educational attainment, and wealth, the odds of reporting ever experiencing IPV are not significantly associated with having four or more ANC visits.

\section{Discussion}

The study sought to establish the relationship between IPV and socio-demographic characteristics, on one hand, and how IPV is associated with use of maternal health care, on the other hand. The findings show that $43 \%$ of women who have ever been in an intimate relationship and who had a birth in the five years preceding the survey have ever experienced IPV. The prevalence of IPV reported in this study is relatively high and requires concerted efforts from stakeholders to address this widespread problem.

Socio-demographic characteristics that were significantly associated with reporting IPV in the study include women's marital status, household wealth, witnessing parental violence, and attitudes justifying wife beating. These findings are in some respects consistent with previous studies, and contrasting in others. Previous studies in developing countries have reported a significant relationship between household wealth and experiencing IPV (Yount and Carrea, 2006; Luke, Schuler, Mai, Vu Thien and Minh, 2007; Kwagala et al, 2013). In contrast, this study found that women in the middle wealth quintile had higher odds of reporting IPV. Similar results are found marginally for Zambia and Bolivia, in a multi-country study by Hindin et al. (2008). A backlash hypothesis within the feminist discourse may be appropriate for interpreting findings of a relationship between higher levels of wealth and increased prevalence of IPV. It asserts that men who direct violence toward empowered women may be threatened by the loss of authority, power, and masculinity status due to the social mobility of women, and use violence as a means to keep women in "their place" so as to maintain the status quo (Brownmiller, 1975).

The findings on attitudes justifying wife beating and having witnessed parental violence agree with other studies done in Africa (Antai, 2011; Kwagala et al, 2013; Gage and Hutchinson, 2006; Klomegah, 2008; Hindin et al., 2008). The finding that IPV victims often justify wife beating reflects both the persistence of cultural norms that privilege men with power over women (Simpson, 2005; Fourie, 2004; Dover, 2005) and also the lack of progress in the fight against gender inequality in the Zambian society. The same explanation suffices for the link between being a victim of violence and having witnessed parental violence. Women who grew up witnessing violence between their parents may be more likely to accept it as part of everyday life.

Men's jealousy and alcohol consumption are common predictors of intimate partner violence against women in Africa (Koenig et al., 2003; Kimuna and Djamba, 2008). These two factors could be constructed as precursors to the enactment of violence against women, which in a male-dominated society like Zambia is plausible (OMCT, 2002). However, the causal direction between consuming alcohol and perpetrating IPV is confounding. It is not clear whether alcohol consumption causes violence against women or the desire to commit physical or sexual violence against women causes alcohol consumption.

Contrary to other studies elsewhere (Antai, 2011; Kwagala et al, 2013), this study did not find occupation, educational attainment, and area of residence to be significantly associated with IPV in the adjusted model. This difference in findings should help to highlight the importance of analysing factors specific to the population under study.

The second part of our analysis, which examined the relationship between IPV and use of maternal health care, shows a significant relationship only between IPV and facility delivery at the bivariate level, which shows that women who reported ever experiencing IPV are less likely to deliver at a health facility compared with women who reported never experiencing IPV. But after adjusting for key socio-demographic factors, such as area of residence, educational attainment, birth order, and wealth, the analysis did not find place of delivery or number of ANC visits to be significantly associated with IPV. This finding means that the odds of accessing maternal health and antenatal care are not significantly different between women who reported ever experiencing IPV and those who reported never experiencing it. These findings are consistent with other studies done in Zambia (Hindin et al., 2008; Stewart, Sommerfelt, Borwankar, Oluwole, Fogg... Goings, 2010) and in Nepal (Tuladhar et al., 2013).

It is important to explore the reasons that encourage women to go for antenatal checks and subsequently deliver in a health facility, despite experiencing physical or sexual violence. It may be that women who experience spousal violence 
fear the health risks to the unborn baby and thus are motivated to ensure its safety by consistently complying with the recommended number of ANC visits and by delivering at a health facility. Another reason could be that male partners become involved in encouraging their wives to attend ANC and deliver at a health facility regardless of their violent behaviour because of the symbolic meaning attached to children as wealth for the family and a source joy and privilege (Koech and Njoroge, 2014). This can act as a motivation for men to be helpful during the process of childbirth.

The availability of health care services, community knowledge, and acceptance of maternal health services also influence use of maternal health care services (Lubbock and Stephenson, 2008). Where maternal health services are easily accessible and women know the importance of accessing these services, there is a high likelihood that they will use such services, even when facing IPV victimization. This may be true for Zambia because of the strides the country has made in providing maternal health services in the last 5-10 years. The 2013-2014 ZDHS reported that 96\% of mothers received ANC from a skilled provider (a doctor, clinical officer, nurse, or midwife) for their most recent birth in the five years preceding the survey, and $68 \%$ of births took place in a health facility.

This study has strengths and limitations. Firstly, it is probable that sensitive topics such as physical and sexual violence always suffer from underreporting due to many cultural and other underlying factors. Thus, it is likely that it underestimates prevalence of IPV among the selected sample population. The second limitation is that the cross-sectional nature of the study design used in the DHS limits determination of causality between the variables. Also, the definition of ever experiencing physical or sexual violence used in this study may not reflect the current situation, and cannot help in deciphering whether the violence was in fact committed by the woman's current partner. These limitations notwithstanding, using DHS data has important strengths. The survey uses probability sampling procedure to select participants from the entire country, which validates generalisation of the findings to the whole population, and its standard form allows for comparability within and between countries and between repeat surveys. Data are collected through a carefully designed questionnaire by highly experienced interview teams with extensive training and supervision.

\section{Conclusion}

The current study found that in Zambia the socio-demographic characteristics of women that are associated with experience of IPV include marital status, household wealth, occupational status, witnessing parental violence, and attitudes justifying wife beating. Partner characteristics include alcohol consumption and jealousy. The study also discovered that IPV is not strongly associated with use of maternal health care except at a bivariate level, where place of delivery is associated with IPV. These findings underscore the importance of addressing issues of gender equality and problematic cultural norms embedded in our society that make women vulnerable to IPV. Although the relationship between IPV and use of maternal health care was not found to be statistically significant, its direction gives important insight that calls for the need to continue with programmes aimed at increasing access to and knowledge about maternal health care services.

\section{Acknowledgements}

The authors wish to convey their gratitude to the United States Agency for International Development (USAID) for funding the research project through the DHS Fellows Program implemented by ICF International. We are grateful to Dr. Wenjuan Wang, Dr. Sarah Staveteig, Adinan Juma, Henock Yebyo, Dr. Ann Mwangi and Rebecca Winter for commenting on our manuscript.

\section{References}

Antai, D. (2011). Controlling behavior, power relations within intimate relationships and intimate partner physical and sexual violence against women in Nigeria. BMC Public Health, 11, 511. https://doi.org/10.1186/1471-2458-11-511

Bazargan-Hejazia, S., Mohammadi, S. M. R., Lin, J., \& Dalal, K. (2013). Patterns of intimate partner violence: A study of female victims in Malawi. Journal of Injury and Violence, 5(1), 38-50. https://doi.org/10.5249/jivr.v5i1.139

Bell, K. M., \& Naugle. (2008). Intimate partner violence theoretical considerations: moving towards a contextual framework. Clinical Psychological Review, 28(7), 1096-1107. https://doi.org/10.1016/j.cpr.2008.03.003

Birmeta K., Dibaba, Y., \& Woldeyonnes, D. (2013). Determinants of maternal health care utilization in Holeta Town Central Ethiopia. BMC Health Services Research, 13, 256. https://doi.org/10.1186/1472-6963-13-256

Bongaarts, J., Cleland, J., Townsend, J W., Bertrand, J. T., \& Gupta, M. D. (2012). Family Planning Programs for the 21st Century: Rationale and Design. New York, New York, USA: The Population Council.

Brownmiller, S. (1975). Against Our Will: Men, Women, and Rape. New York: Fawcett-Columbine.

Campbell, J. C. (2002). Health consequences of intimate partner violence. Lancet, 359(9314), 1331-1336. https://doi.org/10.1016/S0140-6736(02)08336-8 
Central Statistical Office (CSO) [Zambia], Ministry of Health (MOH) [Zambia], and ICF International. (2009). Zambia Demographic and Health Survey 2007. Rockville, Maryland, USA: Central Statistical Office, Ministry of Health, and ICF International.

Central Statistical Office (CSO) [Zambia], Ministry of Health (MOH) [Zambia], and ICF International. (2014). Zambia Demographic and Health Survey 2013-2014. Rockville, Maryland, USA: Central Statistical Office, Ministry of Health, and ICF International.

Devries, K. M., Mak, J. Y. T., Garcia-Moreno, C., Petzold, M., Child, J. C., Falder, G., \& Watts, C. H. (2013). The global prevalence of intimate partner violence against women. Science, 340, 1527-1528. https://doi.org/10.1126/science.1240937

Diop-Sidibe, N., Campbell, J. C., \& Becker, S. (2006). Domestic violence against women in Egypt-wife beating and health outcomes. Social Science \& Medicine, 62(5), 1260-1277. https://doi.org/10.1016/j.socscimed.2005.07.022

Dover, P. (2005). Expectations of Manliness in a Zambian Village. In: African Masculinities. Durban: University of Kwazulu Natal Press. https://doi.org/10.1057/9781403979605_11

Emenike, E., Lawoko, S., \& Dalal, K. (2008). Intimate partner violence and reproductive health of women in Kenya. International Nursing Review, 55(1), 97-102. https://doi.org/10.1111/j.1466-7657.2007.00580.x

Felson, R. B., \& Messne, S. F. (2000). The control motive in intimate partner violence. Social Psychology Quarterly, 63, 84-94. https://doi.org/10.2307/2695883

Gage, S., \& Hutchinson, P. (2006). Power, control and intimate partner sexual violence in Haiti. Archives of Sexual Behavior, 35, 11-26. https://doi.org/10.1007/s10508-006-8991-0

Garcia-Moreno, C., Jansen, H. A., Ellsberg, M., Heise, L., \& Watts, C. H. (2006). Prevalence of intimate partner violence: Findings from the WHO multi-country study on women's health and domestic violence. Lancet, 368(9543), 1260-1269. https://doi.org/10.1016/S0140-6736(06)69523-8

Hinden, M. J. (2003). Understanding women's attitudes towards wife beating in Zimbabwe. Bulletin of the World Health Organization, 81, 501-508.

Hindin, M. J., \& Adair, L. S. (2002). Who's at risk? Factors associated with intimate partner violence in the Philippines. Social Science and Medicine, 55(8), 1385-1399. https://doi.org/10.1016/S0277-9536(01)00273-8

Hindin, M. J., Kishor, S., \& Ansara, L. D. (2008). Intimate Partner Violence and Couples in 10 DHS Countries: Predictors and Health Outcomes. DHS Analytical Studies No. 18. Calverton, MD USA: Macro International Inc.

Jewkes, R. (2002). Intimate partner violence: Causes and prevention. Lancet, 359(9315), 1423-1429. https://doi.org/10.1016/S0140-6736(02)08357-5

Jewkes, R., Levin, L., \& Penn-Kekana, L. (2002). Risk factors for domestic violence: Findings from a South African cross-sectional study. Social Science \& Medicine, 55(9), 1603-1617. https://doi.org/10.1016/S0277-9536(01)00294-5

Kimuna, S. R., \& Djamba, Y. K. (2008). Gender based violence: Correlates of physical and sexual wife abuse in Kenya. Journal of Family Violence, 23(5), 333-342. https://doi.org/10.1007/s10896-008-9156-9

Klomegah, K. (2008). Intimate partner violence (IPV) in Zambia: An examination of risk factors and gender perceptions." Journal of Comparative Family Studies. Available online at http//www.jstor.org/stable. Accessed on $12 / 06 / 2015$.

Koech, P, K., \& Njoroge, N. (2014). Changes in the Traditional African concept of the Child and Childhood: The Aftermath with reference to Kenya. Nairobi: Kenya University http://www.academia.edu/6721975/Changes_in_the_Traditional_African_concept_of_the_Child_and_Childhood_ The_Aftermath_with_reference_to_Kenya. Accessed: 14/12/2015.

Koenig, M. A., Lutalo, T., Zhao, F., Nalugoda, F., \& Wabwire-Mangen, F. (2003). Domestic violence in rural Uganda: Evidence from a community-based study. Bulletin of the World Health Organization, 81(1), 53-60.

Krug, E. G., Mercy, J. A., Dahlberg. L. L., \& Zwi, A. B. (2002). The World Report on Violence and Health. Geneva, Switzerland: World Health Organization (WHO).

Kwagala, B., Wandera, S. O., Ndugga, P., \& Kabagenyi, A. (2013). Empowerment, partner's behaviours and intimate partner physical violence among married women in Uganda. BMC Public Health, 13, 1112. https://doi.org/10.1186/1471-2458-13-1112

Lawoko, S., Dalal, K., Jiayou, L., \& Jansson, B. (2007). Social inequalities in intimate partner violence: A study of women in Kenya. Violence and Victims, 22(6), 773-784. https://doi.org/10.1891/088667007782793101

Luke, N., Schuler, S. R., Mai, B. T., Vu Thien, P., \& Minh, T. H. (2007). Exploring couple attributes and attitudes and marital violence in Vietnam. Violence Against Women, 13(1), 5-27. https://doi.org/10.1177/1077801206295112 
Ofei-Aboagye, O. R. (1994). Altering the strands of the fabric: A preliminary look at domestic violence in Ghana. Feminism and the Law, 19(4), 924-938. https://doi.org/10.1086/494945

Okenwa, L., Lawoko, S., \& Jansson, B. (2011). Contraception, reproductive health and pregnancy outcomes among women exposed to intimate partner violence in Nigeria. European Journal of Contraception and Reproductive Health Care, 16(1), 18-25. https://doi.org/10.3109/13625187.2010.534515

Ononokpono, N. D., \& Azfredrick, C. E. (2014). Intimate partner violence and the utilization of maternal health care services in Nigeria. Health for Women International, 35, 973-989. https://doi.org/10.1080/07399332.2014.924939

Rahman M., Nakamura, K., Seina, K., \& Kizuki, M. (2012). Intimate partner violence and use of reproductive health services among married women: Evidence from a National Bangladesh sample. BMC Public Health, 22, 913. https://doi.org/10.1186/1471-2458-12-913

Sharps, P. W., Laughon, K., \& Giangrande, S. K. (2007). Intimate partner violence and the childbearing year: Maternal and infant health consequences. Trauma Violence Abuse, 8(2), 105-116. https://doi.org/10.1177/1524838007302594

Shezongo-Macmillan, J., Kasese-Kumalo, H., Mohamed-Redi, M., Kasonde-Ngandu, S., Mbozi, E., Ntalasha, H., ... Chanda, A. (2007). Women's Sexual and Reproductive Rights and HIV/AIDS Transmission in Zambia. WILSA Educational Research Trust.

Simpson, A. (2005). Sons and fathers/boys to men in the time of AIDS: Learning masculinity in Zambia. Journal of Southern African Studies, 31(3), 569-586. https://doi.org/10.1080/03057070500202873

Smith, P. H., Tessaro, I., \& Earp, J. L. (1995). Women's experiences with battering: A conceptualization from qualitative research. Women's Health Issues, 5, 173-182. https://doi.org/10.1016/1049-3867(95)00615-X

Stewart, H., Sommerfelt, E., Borwankar, R., Oluwole, D., Fogg, K., \& Goings, S. (2010). Domestic violence against women in sub-Saharan Africa: Associations with maternal health. Presented in commemoration of 16 Days of Activism against Gender Violence 2010. Retrieved on 20/04/2015 from www.igwg.org/igwg_media/domestic_violence_presentation.pdf

Suffitz, J. (2010). Understanding gender-based violence: Evidence from Kilimanjaro. African Sociological Review, 14(1), 84-101.

Taillieu, T. L., \& Brownridge, D. (2010). Violence against pregnant women: Prevalence, patterns, risk factors, theories, and directions for future research. Aggression and Violent Behavior, 15, 14-35. https://doi.org/10.1016/j.avb.2009.07.013

Tuladhar, S., Khanal, K. R., Lila, K. C., Ghimire, P. K., \& Onta, K. (2013). Women's Empowerment and Spousal Violence in Relation to Health Outcomes in Nepal: Further Analysis of the 2011 Nepal Demographic and Health Survey. Calverton, Maryland, USA: Nepal, Ministry of Health and Population, New ERA, and ICF International.

UNICEF. (2000). Violence against women and girls. Innocenti Digest, No. 6.

Vyas, S., \& Watts, C. (2009). How does economic empowerment affect women's risk of intimate partner violence in low and middle income country settings?: A systematic review of published evidence. Journal of International Development, 21, 577-602. https://doi.org/10.1002/jid.1500

World Health Organisation (WHO). (2013). Global and regional estimates of violence against women: prevalence and health effects of intimate partner violence and non-partner sexual violence. Geneva: WHO

World Health Organization, UNICEF, UNFPA, The World Bank, and the United Nations Population Division. (2014). Trends in Maternal Mortality: 1990-2013. Estimates by WHO, UNICEF, UNFPA, The World Bank, and the United Nations Population Division. Geneva, Switzerland: WHO.

World Organisation Against Torture (OMCT). (2002). Violence Against Women: A Report Prepared for the UN Committee on the Elimination of Discrimination Against Women. Geneva, Switzerland.

Yount, K. M., \& Carrera, J. S. (2006). Domestic violence against married women in Cambodia. Social Forces, 85(1), 355-387. https://doi.org/10.1353/sof.2006.0151

Zacarias A. E., Macassa, G., Svanström, L., Soares, J. F., \& Antai, D. (2012). "Intimate partner violence against women in Maputo city, Mozambique." BMC International Health and Human Rights, 12(1), 35. https://doi.org/10.1186/1472-698X-12-35

\section{Copyrights}

Copyright for this article is retained by the author(s), with first publication rights granted to the journal.

This is an open-access article distributed under the terms and conditions of the Creative Commons Attribution license which permits unrestricted use, distribution, and reproduction in any medium, provided the original work is properly cited. 